Journal of Animal and Veterinary Advances 10 (12): 1523-1525, 2011

ISSN: $1680-5593$

(C) Medwell Journals, 2011

\title{
Bovine Herpesvirus Type 1 (BHV-1) Prevalence in Dairy Cattle
}

\author{
Uzeyir Taha Iscan and Rustem Duman \\ Graduate School of Natural and Applied Sciences, Department of Biology, \\ Selcuk University, 42031 Konya, Turkey
}

\begin{abstract}
In this study, Bovine Herpesvirus type 1 (BHV-1) prevelance causing Infectious Bovine Rhinotracheitis (IBR) in dairy cattle that showed respiratory system symptoms and that were located in Iskilip, Corum situated in Middle Black Sea Region in Turkey were studied. For this purpose, owned by small family enterprises and not vaccinated, 5200 animals over 1 year old were scanned and nasal swap and blood samples were taken from 250 animals showing respiratory system disease symptoms and having body temperature above normal. Total 250 nasal swap samples and blood samples from the same cattle were tested, respectively against antigen and antibody presence for BHV-1 by ELISA kits obtained commercially. For the sampled cattle, BHV-1 antigen prevelance was detected as $0.8 \%(2 / 250)$. During the serological part of the study, for the same sampled animals, BHV-1 specific antibody prevelance was detected as $21.2 \%(53 / 250)$. Consequently, BHV-1 infection presence/extensity was detected in cattle owned by family enterprises in Iskilip vicinity and it was agreed that serious precautions should be taken to control the infection.
\end{abstract}

Key words: Bovine herpesvirus type 1, antigen, antibody, dairy cattle, ELISA, infection

\section{INTRODUCTION}

Bovine Herpesvirus-1 (BHV-1) infection is an acute, contagious and inflammatory viral disease seen in domestic and wild cattle. BHV-1 is an economically important disease characterized by severe inflammation of upper respiratory tract together with dyspnea, depression, nasal flow and deconditioning (Yavru et al., 2005). Besides this infection may cause acute gastroenteritis, conjunctivititis, encephalitis, abortion, mastitis and repeat breeder phenomena in cattle (Fenner et al., 1993; Ata et al., 2006, 2008).

This study was carried out to detect BHV-1 prevelance, introducing BHV-1 presence virologically and serologically by ELISA kits obtained commercially in nasal swap and blood serum samples from 250 infected cattle owned by small family enterprises and having clinically upper respiratory tract disease symptoms in Iskilip region (body temperature above normal, nasal and lacrima flow, stagnancy state etc.).

\section{MATERIALS AND METHODS}

Animals: In the study, total 250 dairy cattle were sampled for respiratory system disease symptoms by scanning 5200 unvaccinated animals over 1 year old that were owned by small family enterprises in Iskilip, Corum.
Nasal swap samples: Nasal swap samples were taken from 250 cattle showing respiratory system symptoms. Collection kits obtained commercially from Bio-X Diagnostics (Belgium) were used to collect nasal fluid.

Blood samples: Blood samples taken into polystyrene tubes with kaoline in sterile conditions were centrifuged for $10 \mathrm{~min}$ at $2000 \mathrm{rpm}$ for the serum to seperate. Obtained serum was then inactivated in water-bath at $56^{\circ} \mathrm{C}$ for $30 \mathrm{~min}$ and was kept in deep freezer at $-20^{\circ} \mathrm{C}$ as sections of $1 \mathrm{~mL}$ until used in the test.

BHV-1 ELISA (antigen): To detect BHV-1 antigen in nasal swap samples, ELISA kit (Bio-X Pulmotest BHV-1 (BIO K 189) obtained commercially from Bio-X Diagnostic firm (Belgium) was used.

BHV-1 ELISA (antibody): To detect BHV-1 specific antibody in blood serum samples, commercial ELISA test kit (ELISA IBR Serum and Milk Screening, Version: P03140/04, Institut Pourquier, France) was used according to its procedure.

\section{RESULTS AND DISCUSSION}

In the study, as a result of ELISA tests applied to nasal swap and blood serum samples from 250 unvaccinated cattle while BHV-1 antigen prevelance in

Corresponding Author: Rustem Duman, Graduate School of Natural and Applied Sciences, Department of Biology, Selcuk University, 42031 Konya, Turkey 
Table 1: Results of ELISA antigen and antibody of sampled animals

\begin{tabular}{|c|c|c|c|c|c|}
\hline \multirow[b]{2}{*}{ Settlement area } & \multirow{2}{*}{$\begin{array}{c}\text { Number of } \\
\text { sampled animals }\end{array}$} & \multicolumn{2}{|c|}{ BHV-1/Antigen } & \multicolumn{2}{|c|}{ BHV-1/Antibody } \\
\hline & & + & $\%$ & + & $\%$ \\
\hline Iskilip (Corum) & 250 & 2 & 0.8 & 53 & 21.2 \\
\hline
\end{tabular}

sampled cattle was detected as $0.8 \%(2 / 250)$, BHV-1 specific antibody seroprevelance in the same sampled animals was detected as $21.2 \%(53 / 250)$ (Table 1$)$.

BHV-1 known to cause IBR in cattle is seen all over the world except a few countries such as Switzerland, Denmark and Finland where the disease was completely eradicated (Ackermann et al., 1990). Results on BHV-1 antibody prevelance in this study $(21.2 \%)$ were compatible with prevelance rates found by Ghram and Minocha (1990) in Tunisia 25.9\%, Tekes et al. (1999) in small cattle herds in Hungary $13.5-15.7 \%$, Ata et al. (2006) in cows in Burdur region $11.94 \%$ and in heifers $14.60 \%$ in cattle in Konya and around $15.8 \%$ but were lower than the prevelance rates introduced by serological studies applied in other places; $57.08 \%$ (Yavru et al., 2005) and 35.08 and $38.75 \%$ (Duman et al., 2007). However, it is quite natural that rates of exposal to the factor vary for herds in different settlements and in different care and feeding conditions (Ackermann and Engels, 2006). In this study, cattle were sampled from small family enterprises where the animals were only 5-6 altogether. It was reported that infection rates detected in family class enterprises where less animals were grown were lower than those in organized enterprises where many animals were grown intensively and the reason for this might be determined as less posibility of contamination among animals depending on small amount of animals in small family enterprises (Tekes et al., 1999; Woodbine et al., 2009). On the other hand, samplings in this study were done during summer. BHV-1 infection prevelance was reported to be usually lower in summer than in the other seasons (Woodbine et al., 2009).

In this study although, a seropositivity against BHV-1 was detected at a rate of $21.2 \%$, a lower antigen prevelance $(0.8 \%(2 / 250))$ was found at the end of examining 250 nasal swap samples from the same animals by commercially obtained antigen ELISA (Table 1). Besides, antibody presence particular to BHV-1 couldn't be detected in blood serum samples of these two antigen positive animals. This condition shows us that these two animals were acute-infected.

Following BHV-1 infection, the virus becomes latent in ganglions and the animal remains seropositive all life long, the virus can be reactivated by stress and such animals are possible to spread the virus around the environment periodically (OIE, 2008). This phenomena might have caused the positive samples to have been detected at lower rates in detecting viral antigens by
ELISA. As a matter of fact, to detect BHV-1 prevelance in cattle dispatched to market in Southern state of Zambia, Mweene et al. (2003) studied 116 nasal secretion samples by direct Fluorescent Antibody Test (FAT) while they studied the blood samples from the same cattle by commercially obtained ELISA kit found the average prevelance of BHV-1 antibodies as $48.28 \%$ (56/116) and found the prevelance of BHV-1 antigens as $23.28 \%$ $(27 / 116)$. On the other hand, the reason for detecting a lower antigen prevelance rate than antibody prevelance rate in sampled animals may be because sensitivity and specifity of antigen-ELISA was less than the other methods (virus isolation and PCR) used to diagnose the virus directly. For detecting antigens specific to $\mathrm{BHV}-1$, Mahmoud and Ahmed (2009) stated that PCR was more sensitive, faster and more effective than methods used to diagnose the virus quickly and antibody-ELISA was more sensitive in detecting BHV-1 antibodies. Therefore, in detecting antigen presence particular to BHV-1 using PCR as well as antigen-ELISA could be favorable in detecting latent infections in cattle.

\section{CONCLUSION}

Consequently, BHV-1 infection/extensity in cattle owned by family enterprises in Iskilip region was determined and it was agreed that serious precautions should be taken to control the infection.

\section{ACKNOWLEDGEMENT}

This study was supported by the Scientific Research Projects Commission of Selcuk University (Project number: 09201062).

\section{REFERENCES}

Ackermann, M. and M. Engels, 2006. Pro and contra IBR-eradication. Vet. Microbiol., 113: 293-302.

Ackermann, M., H.K. Muller, L. Bruckner and U. Kihm, 1990. Eradication of infectious bovine rhinotracheitis in Switzerland: Review and prospects. Vet. Microbiol., 23: 365-370.

Ata, A., M. Kale, S. Yavru, O. Bulut and U. Buyukyoruk, 2006. The effect of subclinical bovine herpesvirus 1 infection on fertility of cows and heifers. Acta Vet., 56: 267-273.

Ata, A., M. Kocamuftuoglu, S. Hasircioglu and M. Kale, 2008. Investigation of bovine herpesvirus-1 (BHV-1) infection in relation to fertility in repeat breeder cows. Proceedings of the 16th Congress of the Mediterranean Federation for Health and Production of Ruminants, April 26, Zadar, Croatia, pp: 63-69. 
Duman, R., S. Yavru, O. Bulut and M. Kale, 2007. A serological survey of bovine herpesvirus- 1 infection in beef herds in Turkey. Indian Vet. J., 84: 1026-1028.

Fenner, F.J., E.P.J. Gibbs, F.A. Murphy, R. Rott, M.J. Studdert and D.O. White, 1993. Herpesviridae. In: Veterinary Virology, Fenner, F.J., E.P.J. Gibbs, F.A. Murphy, R. Rott, M.J. Studdert and D.O. White (Eds.). Academic Press Inc., San Diego, USA., pp: $337-368$.

Ghram, A. and H.C. Minocha, 1990. Neutralizing antibodies to bovine herpesvirus-1 (BHV-1) and bovine parainfluenza-3 (PI-3) viruses in cattle in Tunisia. Arch. Inst. Pasteur. Tunisia, 67: 25-31.

Mahmoud, M.A. and S.A. Ahmed, 2009. Prevalence of bovine herpesvirus-1 in sheep and goats in Egypt. Global Veterinaria, 3: 472-479.

Mweene, A.S., H. Fukushi, G.S. Pandey, M. Syakalima and M. Simuunza et al., 2003. The prevalence of bovine herpesvirus-1 in traditional cattle in Southern Province, Zambia. Rev. Sci. Tech., 22: 873-877.
OIE, 2008. Manual of Diagnostic Tests and Vaccines for Terrestrial Animals. OIE, Paris, France, pp: 1343.

Tekes, L., B. Markos, S. Kecskemeti, J. Mehesfalvi, Z. Mate and E. Kudron, 1999. Prevalence of bovine herpesvirus 1 (BHV-1) infection in Hungarian cattle herds. Acta Vet. Hung., 47: 303-309.

Woodbine, K.A., G.F. Medley, S.J. Moore, A.M. Ramirez-Villaescusa, S. Mason and L.E. Green, 2009. A four year longitudinal sero-epidemiological study of bovine herpesvirus type-1 (BHV-1) in adult cattle in 107 unvaccinated herds in south west England. BMC Vet. Res., 5: 5-5.

Yavru, S., A. Simsek, O. Yapkic and M. Kale, 2005. Serological evaluation of viral infections in bovine respiratoy tract. Acta Vet. Beograd, 55: $219-226$ 